\title{
Lumbar Spine X-Ray as a Standard Investigation for all Low back Pain in Ghana: Is It Evidence Based?
}

\author{
Abena Y. Tannor \\ Ghana Med J 2017; 51(1): 24-29 DOI: http://dx.doi.org/10.4314/gmj.v51i1.5
}

Family Medicine Department, Komfo Anokye Teaching Hospital, P.O. Box 1934, Kumasi, Ghana

Corresponding author: Dr. Abena Yeboaa Tannor

E-mail: bbyadjei@yahoo.com

Conflict of interest: None declared

\begin{abstract}
SUMMARY
Background: Low back pain (LBP) has a prevalence of $84 \%$ in Africa. The commonest form of imaging is plain lumbar spine $\mathrm{x}$-ray. It gives a radiation dose equivalent to 65 times a chest $\mathrm{x}$-ray dose and sends one of the highest doses to the human reproductive organs. The commonest cause of LBP in Africa is degenerative disease. X-ray findings do not change mode of treatment yet most physicians still routinely request for $\mathrm{x}$-rays.

Methods: This is a systematic review of databases including The Cochrane, CINAHL plus, AMED, and MEDLINE. Key evidence was clinical guidelines on $\mathrm{x}$-ray use for low back pain. Key search terms included low back pain, $\mathrm{x}$ rays, guidelines, Ghana.

Results: Four clinical guidelines on LBP emerged from two Systematic Reviews rated excellent and four good Randomized Controlled Trials: The European guidelines for acute and sub-acute non-specific Low Back Pain, The American College of Physicians and the American Pain Society guideline for diagnostic imaging for Low Back Pain, The NICE guidelines for persistent non-specific Low Back Pain and the Ghana Standard Treatment Guidelines (GSTG). All the guidelines agree that a good history and clinical examination for all LBP patients helps in diagnosing. Only GSTG recommends routine plain spinal x-rays.

Conclusion: There is strong evidence indicating very little benefit from routine lumbar spine $\mathrm{x}$-rays for all LBP. The GSTG needs to be revised considering the increased risks of radiation exposure and the x-ray costs.
\end{abstract}

Funding: None declared

Keywords: low back pain, investigations, x-rays, guidelines, Ghana

\section{INTRODUCTION}

Low back pain is the commonest musculoskeletal condition accounting for $30-40 \%$ of visits to rheumatologists in sub - Saharan Africa. ${ }^{1}$ The lifetime prevalence of low back pain is known to be $84 \%$ worldwide causing disability in $11-12 \%$ of the world's population. ${ }^{2}$

It thus ranks sixth among the DALYs (disability adjusted life years) causing diseases and injuries. ${ }^{3}$ Although research initially concluded that the prevalence of low back pain was higher in developed countries, a systematic review of low back pain in Africa revealed a prevalence comparable to that of developed countries. ${ }^{4}$

Low back pain is usually grouped as specific, having a suspected pathological cause, and non-specific, having an unknown cause. It can also be classified as acute lasting less than 6 weeks, sub-acute - lasting between 6weeks and 12 weeks and chronic- lasting more than 12 weeks. $^{5}$
Imaging of the spine is one of the investigations for low back pain with plain $x$-ray of the lumbar spine being the commonest means of imaging. The anterior-posterior and lateral views of the lumbar spine on x-ray evaluate lumbar alignment, vertebral body and disk space size, bone space and architecture, and gross evaluation of soft tissue structures. ${ }^{6}$ Lumbar spine $\mathrm{x}$-ray however accounts for one of the highest radiation doses to the reproductive organs of a human being and is equivalent to about 65 times the dose for a chest $\mathrm{X}$-ray. ${ }^{7,8}$

Requests for lumbar spine x-rays unfortunately continues to be high among physicians and even physiotherapists before treatment for low back pain. This was confirmed in a qualitative study9 on General Practitioners in Norway, the Netherlands and the USA and in a systematic review of 33 RCTs10which revealed unnecessary x-ray requests for low back pain. 
This is contrary to results of studies which reveal that findings of degenerative changes of the spine on $x$-ray which accounts for most causes of back pain do not alter its management and causes due to tumour or infection are also not common. ${ }^{11,12}$ The WHO's 2013 update paper on low back pain states categorically that the risks of high doses of lumbar spine $\mathrm{x}$ ray radiation do not justify its routine use. ${ }^{13}$

The above situation of over utilization of lumbar spine $\mathrm{x}$-rays for all low back pain by physicians is not any different in African countries like Ghana. Since the prevalence of low back pain in Africa has gradually increased over the years, its management including investigations should be well structured to prevent improper diagnoses, incorrect treatment and hence pressure on the already constrained health care resources in Africa. This review therefore seeks to evaluate guidelines on the use of lumbar spine $\mathrm{x}$-rays as an investigational tool for all low back pain, comparing it to existing guidelines in Ghana.

\section{METHODS}

Key evidence for this review was clinical guidelines on the use of lumbar spine x-ray for all low back pain. A search was performed on the St George's University library website using databases including The Cochrane Library, CINAHL plus, AMED, and MEDLINE as well as Google scholar and Google.

Key search terms used included low back pain, investigations for back pain, x-rays, guidelines, management, Africa, Ghana. Only guidelines in English were considered and reference lists of included guidelines were added for further information. After a critical review of the search results, guidelines and articles not relevant to the subject in question were excluded.

\section{RESULTS}

Four guidelines on back pain ultimately emerged from the search with three of them being based in developed countries and one from Ghana, a developing country. The guidelines that emerged from the search included; the European guideline for acute and sub-acute nonspecific low back pain ${ }^{14}$, the American College of physicians and the American Pain Society guideline for diagnostic imaging for low back pain, ${ }^{15}$ the United Kingdom's (UK) National Institute for Clinical Excellence (NICE) guidelines for persistent non-specific low back pain16and the Ghana Standard Treatment (GST) guidelines. ${ }^{17}$
The quality of the evidence backing the guidelines was then rated (Table 1) using Evans' hierarchy of evidence which ranks research evidence evaluating health care interventions based on effectiveness, appropriateness and feasibility. ${ }^{18}$

Table 1 Evans' hierarchy of evidence used

\begin{tabular}{|c|c|c|c|c|}
\hline EVIDENCE & KEY AUTHOR, DATE & $\begin{array}{l}\text { TYPE } \\
\text { STUDY }\end{array}$ & OF & HIERARCHY \\
\hline \multicolumn{5}{|c|}{ GUIDELINES } \\
\hline \multirow[t]{2}{*}{ European } & Jarvick and Deyo, $2002^{7}$ & $\begin{array}{l}\text { Systematic } \\
\text { view }\end{array}$ & Re- & Excellent \\
\hline & Van Tulder et al, $1997^{19}$ & $\begin{array}{l}\text { Systematic } \\
\text { view }\end{array}$ & Re- & Excellent \\
\hline \multirow[t]{4}{*}{ American } & Djais and Kalim, $2005^{20}$ & $\begin{array}{l}\text { Randomised } \\
\text { trolled } \\
\text { (RCT) }\end{array}$ & $\begin{array}{l}\text { Con- } \\
\text { Trial }\end{array}$ & Good \\
\hline & Kendrick et al, $2000^{21}$ & $\mathrm{RCT}$ & & Good \\
\hline & Kerry et al, $2000^{22}$ & $\mathrm{RCT}$ & & Good \\
\hline & Deyo, $1987^{23}$ & RCT & & Good \\
\hline \multirow[t]{2}{*}{ NICE } & Kendrick et al, $2000^{21}$ & RCT & & Good \\
\hline & Kerry et al, $2000^{22}$ & RCT & & Good \\
\hline
\end{tabular}

\section{The European Guideline}

The European Guideline for acute nonspecific low back pain states that $\mathrm{x}$-rays should not be used for low back pain if there are no clear indications of possible serious pathology or radicular syndrome as it was not associated with improved clinical outcomes but rather an increased workload on General Practitioners (GPs).

It was developed by a multidisciplinary team of specialists in the health sector from eight European countries which had existing guidelines on low back pain. The evidence underlying the guideline was developed from a summary of recommendations from systematic review papers on back pain and a summary of the various guidelines from the European countries using validated search engines.

On the use of x-ray, two systematic review papers on diagnostic imaging were considered in the guideline. Evidence from one of the studies which reviewed 31 papers showed that although there was an association between degenerative changes seen on x-rays and nonspecific low back pain, the findings did not affect the choice of therapy or chances of recovery. Other x-ray findings like spinal bifida, transitional vertebrae, spondylosis and Scheuermann's disease had no significant association with low back pain as they were also found in those without back pain.

The second systematic review concluded that for adults younger than 50 years, $\mathrm{x}$-rays are not useful for low back pain of less than 6 weeks duration unless there was an underlying systematic disease or progressive neurologic deficit. $^{7}$ 


\section{Original Article}

This is because irrelevant findings are common and $\mathrm{x}-$ rays are unlikely to reveal a specific cause. The review however noted that for pain persisting for more than 6 weeks, choice of imaging should depend on clinical findings.

The summary from the guidelines of the participating European countries also noted that $\mathrm{x}$-rays are not useful for non-specific low back pain unless there was a suspicion of serious underlying pathologies or 'red flags'. Red flags include presentation under age 20 or onset over 55, non-mechanical pain, thoracic pain, past history of carcinoma, steroids and HIV, weight loss, widespread neurological symptoms or signs and structural deformity. The Danish Institute for Heath Technology Assessment and the Royal College Clinical Guidelines for the management of Acute Low Back Pain, which were part of the European guidelines, however suggested $\mathrm{x}$-rays as optional in cases of low back pain exceeding 4-6weeks although they added that the risks of high radiation dose from $\mathrm{x}$-rays do not justify routine use.

The American College of Physicians and the American Pain Society guideline

The American College of Physicians and the American Pain Society guideline for diagnostic imaging of low back pain has also stated that for patients with acute, sub-acute and chronic low back pain or low back pain of non-specified duration, routine lumbar $\mathrm{x}$-rays should not be requested but only reserved for patients with severe or progressive neurologic deficits or suspicion of severe underlying condition. This was based on the fact that there was no clinically meaningful effect of routine $\mathrm{x}$ ray for low back pain on patient outcomes except increased cost and a slightly significant increase in patient satisfaction.

The guideline was developed by breaking the topic of low back pain into key questions and using multiple electronic databases in the search. This yielded four RCTs on acute, sub-acute and chronic low back pain which compared the use of routine lumbar x-rays with usual care without $\mathrm{x}$-ray in patients without red flags.

The first study ${ }^{23}$ did not find any difference in the symptom resolution, functional improvement, and satisfaction of patients who had x-rays and those who did not. Kendrick et al's study ${ }^{21}$ on 421 participants was the largest published trial of outcomes of patients who had x-ray of the spine as at 2001. The study noted that the disability and health status scores of both groups of patients at the 3-month follow up were similar except for an increase in patient satisfaction at the 9-month follow up and an increase in the treatment cost of those who had the x-ray.
Kerry et al's study using 153 participants also did not show any difference in the general health of both groups of patients at both the 6 week and one year review except for an increased mental health score on the SF-36 health survey for those who had $\mathrm{x}$-rays. ${ }^{22}$

The fourth study ${ }^{20}$ noted that there was a less than 0.2 in 100 probability of low back pain patients having serious disease which required specific therapy. The study which involved 101 participants also showed that there was no improvement in the health status of patients who had x-ray but rather an increase in the perception of severity of the low back pain leading to illness behaviour and a delayed recovery compared to those who did not have an $\mathrm{x}$-ray.

\section{The NICE Guideline}

The NICE Guideline for the early management of low back pain, states clearly that $\mathrm{x}$-rays of the lumbar spine should not be offered for non-specific low back pain lasting between six weeks to one year. It was developed by a multidisciplinary team including patients who used MEDLINE to develop their search strategies and is the most current guideline on low back pain in Europe that emerged from the search for guidelines.

The guideline concluded that there was no evidence of clinical benefit from referral for $\mathrm{x}$-ray in terms of pain and disability but an increase in patient satisfaction which was however not a primary outcome for the guideline. They also noted that $\mathrm{x}$-rays were not cost effective and that there was evidence of harm to the reproductive system with $\mathrm{x}$-ray use.

The guideline used two high quality RCTs ${ }^{21,22}$ which were also used in the development of the American guidelines with both not noting significant changes in the pain and functional levels of patients who were offered $x$-rays except a slight increase in patient satisfaction.

\section{Ghana Standard Treatment Guidelines}

Ghana has a standard treatment guideline for managing various conditions including low back pain. The guideline was developed by a group of health professionals who concluded that plain spinal $\mathrm{x}$-rays should be requested for low back pain. It also recommends conducting a good clinical history and physical examination of patients presenting with low back pain as well as performing blood investigations. 


\section{DISCUSSION}

\section{Clear Guidelines}

This study sought to review major guidelines on radiographic investigation for low back pain. All the guidelines agree that a good history and clinical examination is paramount in all patients presenting with low back pain as it helps in diagnosing the cause of the back pain.

The European, American and NICE guidelines do not encourage the routine referral for lumbar x-rays. They all however failed to include observational studies in the search for literature on $\mathrm{x}$-ray. This may have eliminated some important information as Barton $^{24}$ noted that RCTs and observational studies which are both high quality can sometimes produce similar results. Observational studies could also provide information in situations where the use of RCTs would be unethical or impractical.

The European guideline which was developed by a team of health specialists with existing low back pain guidelines from eight European countries is however limited to acute non-specific low back pain. This makes the management of chronic low back pain difficult as some of the national guidelines used stated the possible use of x-rays for pain after 4-6 weeks while the rest did not.

The authors in the second systematic review study used to develop the guideline, also acknowledged that they evaluated the quality of methods of data extraction informally and also did not use a formal meta-analysis. ${ }^{19}$ This may affect the quality of the paper as according to Evans although systematic review papers are rated as excellent, their value can be lowered if the research methodology is not robust. ${ }^{18}$ The guideline group however rated the paper as being of high quality.

The American guideline has also been criticized for not using a standardized approach in the inclusion and exclusion criteria and also for including outdated literature although the guideline development group rated that study as of moderate quality. ${ }^{25}$ The largest study ${ }^{21}$ used in developing the American guideline also involved some bias in the methodology as patients who did not consent to randomization were given the option of choosing whether to have an x-ray or not which could have affected their view on the benefits of $\mathrm{x}$-rays.

Ghana is a member of the International Association for the Study of Pain which recommends that $\mathrm{x}$-rays should be reserved for only those in whom red flags are suspected for chronic non-specific low back pain management. The Ghana standard treatment guidelines albeit lists plain spinal $\mathrm{x}$-rays as part of investigations for low back pain work-up but does not specify the type of back pain necessitating radiologic investigation, that is, whether acute, sub-acute or chronic low back pain.

A 10 year hospital based study on low back pain conducted in Togo, Ghana's neighbouring country also noted that the most common cause of low back pain in Sub-Saharan Africa is degenerative disease which can be diagnosed mainly on clinical grounds.

It thus recommended $\mathrm{x}$-rays only for when symptoms suggested infection or tumour. ${ }^{1}$ Schandorf' ${ }^{26}$ study also showed that patients are generally over exposed to radiation in Ghana. This is a source of concern as lumbar spine $\mathrm{x}$-rays provide a high dose of radiation. The study thus recommended the development of a guideline to assist clinicians in referrals for radio diagnostic investigations. Rad-Aid International ${ }^{27}$ also noted that doctors in Ghana do not have stringent training in radiology.

Stating clearly the indications for requesting $\mathrm{x}$-rays in the Ghana Standard Treatment Guidelines also makes it easier for clinicians to manage patients. This is because General Practitioners in Norway, the Netherlands and the USA and a systematic review of 33 RCTs revealed that even though there were guidelines for managing back pain in developed countries, there were still sometimes unnecessary referrals for $\mathrm{x}$-rays by General Practitioners. ${ }^{9,10}$

The authors noted that this was because most of the guidelines were not specific on indications for x-rays and not of practical use to doctors in primary care settings. They thus recommended that guidelines should support each recommendation with adequate explanation, address the need for patient reassurance and also be adaptable to local resources.

A recent Cochrane study ${ }^{28}$ supports the above studies after reviewing interventions for improving the appropriate use of imaging in people with musculoskeletal conditions having noted the overutilization of plain lumbar spine $\mathrm{x}$-rays for uncomplicated acute low back pain. ${ }^{28}$ papers, mainly RCTs were reviewed in the study which revealed that despite the use of educational materials including guidelines, there were still very few significant improvements in the appropriate use of lumbar imaging.

\section{Cost}

The increased cost of $\mathrm{x}$-rays is also one of the factors underlying the NICE, European and American guidelines for pain. The Ghana standard treatment guideline was also aimed at developing cost effective health intervention and providing quality standardized care at an affordable cost. 
The National Health Insurance Scheme which used to cover the cost of x-rays unfortunately no longer covers in majority of health institutions in Ghana. About 31 percent of Ghanaians live below the upper poverty line, many may thus not be able to afford the cost of x-rays .$^{29}$ The guideline's failure to state clearly when to request $\mathrm{x}$-rays for the different types of back pain may thus defeat its main purpose of being cost-effective. The WHO, which governs countries worldwide therefore needs to develop a clear guideline on diagnosing or investigating all kinds of low back pain as recommended in the WHO pain management guideline. ${ }^{30}$

\section{CONCLUSION}

There is strong evidence indicating very little benefit from requesting $\mathrm{x}$-ray for all low back pain without any red flags except in terms of increased patient satisfaction. The increased risks of exposure to radiation and costs as well as increased workload on GPs however outweigh patient satisfaction. Thus even though the Ghana Standard Treatment guideline recommends the use of x-rays for low back pain, it may need revision on the specific indications taking into consideration cost and effects of excessive exposure to radiation.

\section{Limitations}

Possible limitations of this study include inaccessibility of some journals on electronic databases. Some guidelines on low back pain in other African countries were also not available electronically and attempts to contact the researchers for those guidelines proved futile.

\section{REFERENCES}

1. Mijiyawa M, Oniankitan O, Kolani B, Koriko T. Low back pain in hospital outpatients in Lomé (Togo). Joint Bone Spine 2000 Dec 31;67(6):533-8.

2. Balagué F, Mannion AF, Pellisé F, Cedraschi C. Non-specific low back pain. The Lancet. 2012 Feb 10;379(9814):482-91.

3. Hoy D, March L, Brooks P, Blyth F, Woolf A, Bain C, Williams G, Smith E, Vos T, Barendregt J, Murray $\mathrm{C}$. The global burden of low back pain: estimates from the Global Burden of Disease 2010 study. Annals of the rheumatic diseases 2014 Mar 24:annrheumdis-2013.

4. Louw QA, Morris LD, Grimmer-Somers K. The prevalence of low back pain in Africa: a systematic review. BMC Musculoskeletal disorders. 2007 Nov $1 ; 8(1): 1$.

5. Woolf AD, Pfleger B. Burden of major musculoskeletal conditions. Bulletin of the World Health Organization 2003 Sep;81(9):646-56.

6. Haig AJ. Back Pain: A Guide for the Primary Care Physician. ACP Press; 2005
7. Jarvik JG, Deyo RA. Diagnostic evaluation of low back pain with emphasis on imaging. Annals of internal medicine 2002 Oct 1;137(7):586-97.

8. Baker R, Lecouturier J, Bond S. Explaining variation in GP referral rates for x-rays for back pain. Implement Sci. 2006 Aug 2;1:15.

9. Espeland A, Baerheim A. Factors affecting general practitioners' decisions about plain radiography for back pain: implications for classification of guideline barriers-a qualitative study. BMC Health Services Research. 2003 Mar 24;3(1):1.

10. Somerville S, Hay E, Lewis M, Barber J, van der Windt D, Hill J, Sowden G. Content and outcome of usual primary care for back pain:a systematic review. Br J Gen Pract.2008 Nov 1;58(556):790-7.

11. Hollingworth W, Deyo RA, Sullivan SD, Emerson SS, Gray DT, Jarvik JG. The practicality and validity of directly elicited and SF-36 derived health state preferences in patients with low back pain. Health economics. 2002 Jan 1;11(1):71-85.

12. Van den Bosch MA, Hollingworth W, Kinmonth AL, Dixon AK. Evidence against the use of lumbar spine radiography for low back pain. Clinical radiology. 2004 Jan 31;59(1):69-76.

13. Duthey B. Background Paper 6.24 Low back pain.2013

14. Van Tulder M, Becker A, Bekkering T, Breen A, Gil del Real MT, Hutchinson A, Koes B, Laerum E, Malmivaara A. Chapter 3 European guidelines for the management of acute nonspecific low back pain in primary care. European Spine Journal 2006 Mar 11;15:s169-91.

15. Chou R, Qaseem A, Snow V, Casey D, Cross JT, Shekelle P, Owens DK. Diagnosis and treatment of low back pain: a joint clinical practice guideline from the American College of Physicians and the American Pain Society. Annals of internal medicine 2007 Oct 2;147(7):478-91.

16. Savigny $\mathrm{P}$, Kuntze S, Watson $\mathrm{P}$, Underwood M, Ritchie G, Cotterell M, Hill D, Browne N, Buchanan E, Coffey P, Dixon P. Low back pain: early management of persistent non-specific low back pain. London: National Collaborating Centre for Primary Care and Royal College of General Practitioners. 2009 May;14.

17. Ministry of Health, Ghana, Standard Treatment Guidelines. [online]. 2010. [Accessed 12/03/16]. Available from: http://apps.who.int/medicinedocs/documents/s1801 5en/s18015en.pdf

18. Evans D. Hierarchy of evidence: a framework for ranking evidence evaluating healthcare interventions. Journal of clinical nursing 2003 Jan $1 ; 12(1): 77-84$. 
19. vanTulder MW, Assendelft WJ, Koes BW, Bouter LM. Spinal radiographic findings and nonspecific low back pain: a systematic review of observational studies. Spine. 1997 Feb 15;22(4):427-34.

20. Djais N, Kalim H. The role of lumbar spine radiography in the outcomes of patients with simple acute low back pain.APLAR Journal of Rheumatology. 2005 Jun 1;8(1):45-50.

21. Kendrick D, Fielding K, Bentley E, Kerslake R, Miller P, Pringle M. Radiography of the lumbar spine in primary care patients with low back pain: randomised controlled trial. BMJ 2001 Feb 17;322(7283):400-5.

22. Kerry S, Oakeshott P, Dundas D, Williams J. Influence of postal distribution of the Royal College of Radiologists' guidelines, together with feedback on radiological referral rates, on X-ray referrals from general practice: a randomized controlled trial. Family Practice. 2000 Feb 1;17(1):46-52.

23. Deyo RA, Diehl AK, Rosenthal M. Reducing roentgenography use: can patient expectations be altered?. Archives of internal medicine. 1987 Jan 1;147(1):141-5.

24. Barton S. 'Which clinical studies provide the best evidence?',BMJ.2000:321(7256): 255-256.

25. Manchikanti L, Datta S, Derby R, Wolfer LR, Benyamin RM, Hirsch JA. A critical review of the American Pain Society clinical practice guidelines for interventional techniques: part 1. Diagnostic interventions.Pain Physician. 2009 Dec;13(3):E14174.

26. Schandorf C, Tetteh GK. Analysis of dose and dose distribution for patients undergoing selected X-ray diagnostic procedures in Ghana. Radiation protection dosimetry. 1998 Apr 1;76(4):249-55.

27. Rad-Aid International, Radiology Serving the World - Ghana Country Profile.[online].2009.[Accessed12/03/16] Available at: http://beta.rad-aid.org/pdf/Ghana.pdf

28. French SD, Buchbinder R, Green S. Interventions for improving the appropriate use of imaging in people with musculoskeletal conditions. The Cochrane Library.2006 Apr 13.

29. The World Bank Group, Ghana: Poverty Past, Present and Future. [online]. 2010. [Accessed 01/04/2016] Available at: http://web.worldbank.org/WBSITE/EXTERNAL/T OPICS/EXTPOVERTY/EXTPA/0, contentMDK:2 0204450 menuPK:435735 pagePK:148956 piPK: 216618 theSitePK:430367 isCURL:Y isCURL:Y, 00. html.

30. Kumar N. WHO Normative Guidelines on Pain Management.[online]. 2007. [Accessed 01/04/16] Available at: http://www.who. int/medicines/areas/quality_safety/delphi_ study_pain_guidelines.pdf. 